Kim Sterelny*

\title{
Evolutionary Foundations for a Theory of Moral Progress?
}

https://doi.org/10.1515/auk-2019-00XX

\begin{abstract}
Buchanan and Powell develop a concept of moral progress, and build a middle-range theory of how moral progress comes about. They argue on the basis of their view of the evolutionary origins of normative thought that further moral progress towards more inclusive moral and political systems is possible. In doing so the rebut a conservative reading of the evolution of normative thought: a reading that regards the hope for inclusive moral systems as utopian. Buchanan and Powell argue that this 'evoconservative' argumeny overlooks overwhelming evidence of the adaptive plasticity of normative thought. I agree with their rejection of that evoconservative position, but give an alternative account of the evolutionary foundations of normative cognition and its plasticity. But I also argue that there is a gap in their defence of their view of moral progress: it begs the question against exclusive, relational conceptions of the naturalistic foundations of normative obligations and rights. Their account is less fully naturalistic than they seem to suppose, for it lacks a developed account of the natural facts which make normative claims true, and it is not clear that there is an account to be given that would vindicate their inclusive liberal intuitions about the norms we should have.
\end{abstract}

Keywords: evolution of norms, evolution of norm psychology, intergroup conflict and norms, adaptive plasticity and norms, neo-contractarianism, implicit and explicit norms

\section{Introduction}

I take the central message of The Evolution of Moral Progress to consist of three linked claims. First: it is possible to give a theoretically coherent account of the notion of moral progress. Second, it is likewise possible to give a useful mid-range theory of how moral progress comes about. Third, given the practical importance of moral progress and given the truth of the first two claims, moral progress should be (but has not been) a central concern of normative moral and political theory.

*Corresponding author: Kim Sterelny, School of Philosophy, RSSS, Australian National University, e-mail: Kim.Sterelny@anu.edu.au 
While I think Buchanan and Powell have made a plausible case for this package, I think there is a gap in their defence of the first claim. I also have significant reservations about their analysis of the evolutionary history of moral cognition. ${ }^{1}$ However, these reservations do not undermine the most important empirical conclusion they draw from their evolutionary proposal: namely, that human moral cognition is developmentally plastic enough to make 'inclusive' normative systems psychologically possible for normal human agents. So (as far as I can see) they could agree with the alternative account of the evolutionary foundations of norms that I shall sketch, consistently with their main normative project. I begin with the gap, and then move to two sceptical assessments of their foundational evolutionary claims.

\section{What Are the Natural Foundations of Impartial Moral Norms?}

Buchanan and Powell outline an account of moral progress that commits them to a range of substantive moral claims, though ones that are no longer (openly) controversial in WEIRD ${ }^{2}$ countries: humans of all ethnical backgrounds have equal potential and equal claims to moral standing; both genders (all genders?) are equally capable of directing their lives according to their own conception of a good life, and so deserve equal rights and opportunities; animals deserve at least some moral consideration, for at least the gratuitous infliction of pain is wrong; and so on through the liberal democratic consensus of the late $20^{\text {th }}$ century. (Perhaps somewhat weaker now). These claims now generally have some reflection in the institutions of WEIRD countries, and that reflection made some significant difference to lives in those countries. As a result, these changes count as moral progress.

In developing this line of thought, they argue that this cluster of examples of moral progress shows that important views about the nature of moral norms are impoverished. For from within those frameworks, it is difficult or impossible to show that these examples of moral progress are indeed progress. In particular, they point out that strategic conceptions of morality-neocontractarian views of which Gibbard is the paradigm (Gibbard 1990) - cannot vindicate these liberal platitudes (57-59). A view of moral norms in which such norms are explained on

1 More generally, normative cognition and normative guidance, if moral norms are just a special case of a more general capacity for norm psychology.

2 'WEIRD' = 'Western, Educated, Industrial, Rich, Democratic'. 
the basis of long-run, on-average prudence cannot explain the extension of moral concern to agents who can never be part of any economy of cooperation or reciprocation, nor be a threat to that economy. Consider animals; the seriously and permanently disabled; groups that one can safely exploit and intimidate rather than bargain with. We have no long-run, on-average prudential reasons to give their interests any weight. These strategic conceptions of morality predict that such agents will beyond our circle of moral concern, and hence they cannot accommodate the insight that extensions of a notion of just treatment to these cases is genuine moral progress. In my view, strategic conceptions of morality have rather more reserves than this line of argument suggests. If you do not want your children to be cruel in general, encourage them to be kind to pets and other animals. Certainly, we have good reasons to be wary of those taking an interest in inflicting pain, including pain on animals. And those are prudential good reasons. Even so, Buchanan and Powell are largely right. Ben Fraser and I argued that neocontractarian views (and similar strategic conceptions that explain moral norms by appeal to prudential considerations) can vindicate some, but only some, of the core moral claims of the contemporary liberal world (Sterelny/Fraser 2017).

However, these neo-contractarian views also take on a crucial theoretical burden that Buchanan and Powell seem to duck. They give an account of the natural facts in the world that make normative claims true (when they are true). Buchanan and Powell announce that they do not see their project as a response to outright moral nihilism $(2018,15)$, and that is fair enough. But nihilism-blanket scepticism about all moral claims-is one thing; wanting to know the natural facts that make it true that we should care (to some extent) about animals; or that we should care about the poor and powerless in some distant and economically and environmentally unimportant third-world country is another. In their introduction, Buchanan and Powell appear to address this issue, when they give what they take to be a defence, on naturalistic grounds, of these inclusive moral commitments. In their view, defenders of discriminatory treatments of women, of non-white ethnicities, of other groups of humans have been unable to provide a rationale for different, or no, moral status. All such defences have relied on clearly false empirical premises. ${ }^{3}$ So they say:

"if one contends that some persons have a high basic status while others do not, then one owes a justification for the claim that not only establishes that there are differences amongst groups but also that these differences are of the sort and magnitude relevant to making moral

3 With the admittedly difficult case of seriously and permanently cognitively impaired individuals excepted. 
status judgements [...] it would be a mistake to say [...] that in our investigation we are simply assuming, with no good reasons, a status egalitarian view.” (17)

There is a clear response to this challenge: why don't relational properties count as grounds for discrimination or exclusion?" Why isn't 'they are not my people' a sound normative ground? This is not moral nihilism. Rather, it is a normative stance that privileges relational properties over intrinsic ones. To reject it, Buchan and Powell need something they do not offer. They cannot reject strategic conceptions of morality without providing an alternative account of the natural facts to which true normative claims correspond. So there us a gap. Buchanan and Powell cannot claim to give a naturalist, coherent and theoretically satisfactory account of moral progress while maintaining metaethical neutrality on the facts to which true moral claims correspond. Alternatively, of course, they could join Philip Kitcher in opting for some form of non-cognitivism. But that has theoretical burdens of its own: in particular, they would need to show that their preferred version of non-cognitivism was consistent with their view of the role of reasonessential but not sufficient-in driving moral progress. I move now to reservations about the evolutionary foundations of their account.

\section{Inter-group Conflict in the Pleistocene?}

I continue to be more sceptical than Buchanan and Powell about the role of intergroup conflict in early human evolution; that is, human social evolution almost to the Holocene. I have previously argued (i) there is no clear signature of collective violence on human remains until the very end of the Pleistocene. (ii) There are no battle or raiding scenes in Pleistocene cave art. ${ }^{5}$ (iii) The development of projectile weapons, and the associated abilities to stalk and to lie in ambush make chimp-style raids and patrols dangerous, in ways it is not for chimps. (iv) In contrast to skeletal evidence from early farmers, there is little evidence that Pleistocene foragers were routinely resource stressed; that they lived in regimes of near-starvation that compelled a struggle for resources. (v) Jointly, these facts about risks and resource availability suggest that the cost/benefit balance would often favour fairly peaceable relations with neighbours. That is especially true be-

\footnotetext{
4 This is not arbitrary, at least in common moral opinion. In a disaster, Buchanan is morally entitled to save his children, his partner, his friends, before he saves Powell.

5 This archaeological evidence has been recently reviewed in (Kim/Kissel 2018). They agree that there is no smoking gun of Pleistocene warfare, though they also make the fair point that skirmishing and other forms of low-level raiding might not be archaeologically visible.
} 
cause there are positive benefits from peace, not just through trade and risk management (which require quite sophisticated cultural tools), but because territories can be exploited much more efficiently if foragers are not regularly at risk of attack from neighbours. Moreover, forager ethnography certainly shows that while foragers are capable of war, they are also capable of peace (Sterelny 2016).

To these factors I shall add a further observation: organised collective violence is a very demanding form of collective action problem. (i) It requires significant prior investment in the tools of war. (ii) It depends on challenging, precise, and error-intolerant capacities to co-ordinate, often in difficult circumstances; for example, moving at night through unfamiliar country, or coordinated convergence on a single target at a specific time. (iii) Given these coordination challenges, it is very easy for plans to go astray, even when everyone is trying to keep to plan. But the high inherent risks of collective violence generate strong temptations to defect. That temptation must be controlled, typically through some mix of symbolically-mediated loyalties to the rest of the party, serious sanctions for defecting, and credible promises of material and reputational rewards for staying the course. These considerations suggest that most, perhaps all, of the cultural and cognitive tools of behaviourally modern humans have to be in place to make warlike organised violence possible: rich and explicit normative systems; language; groups unified by a shared and mutually recognised identity. War was made possible by the prior evolution of the cultural and cognitive tools that support elaborate and demanding forms of cooperation, and that probably includes norm psychology.

Buchanan and Powell acknowledge the ambiguities of the archaeological record, and agree that there is no smoking gun demonstrating the ubiquity or regularity of intercommunal violence in the Pleistocene. But they are impressed by a feature of human psychology that they take to point to a regular threat of violence: young children rapidly learn to recognise distinctions between their own kind (an in-group) and an out-group. Moreover, it is fairly easy for out-group status to become negatively valanced (130-132). ${ }^{6}$ I agree that this is suggestive. But as Buchanan and Powell themselves argue, hostility to the out-group is not 'hard-wired'. One might expect hostility to be genetically entrenched, if intergroup hostility really had been the default through the Pleistocene. Moreover, while sceptical of the view that hostility was the default, on my view of social life in the Pleistocene, the distinction between one-of-us and not one-of-us certainly mattered enormously. I would be astounded if there was anything like an attitude of default trust towards members of out-groups. Rather, on my analysis,

6 Though this might just be a special case of neophobia. 
the attitude to the out-group was largely strategic, often with mutual tolerance, perhaps sometimes with active cooperation; sometimes with tolerance and peace breaking down. If that picture of late Pleistocene intergroup relations is broadly right, developmental sensitivity to the in-group, out-group distinction would be no surprise.

As far as I can see, there is nothing here that Buchanan and Powell must reject. For their purposes, they need to show that indifference or hostility to out-groups is not so developmentally entrenched as to make it impossible for humans to endorse, act on, and build institutions around 'inclusive' systems of moral norms. The less our psychology was formed in the crucible of inter-group conflict, the better the prospects for demonstrating that form of plasticity of norm psychology. So far so good, but that leads to my next reservation about their evolutionary analysis. I agree that norm psychology is plastic, but I am sceptical about their account of its foundations. So putting together the points just made and those to come, one could reconfigure Buchanan and Powell's argument in the following way: (1) It is unlikely that our norm psychology is an adaptation to make one's own group more effective in situations of inter-group conflict and competition. (2) But even if it were, the pessimistic conclusions drawn from that putative fact about the prospects for moral progress do not follow. (3) For that pessimistic conclusion ignores strong empirical evidence for the plasticity of norm psychology. I think that would be a sound argument, even though I have different views about the origins of that plasticity. I turn to those now.

\section{How Genetically Entrenched is Norm Psychology?}

As just noted, in their discussions of evolutionary accounts of morality, Buchanan and Powell make a very important point, and one that has been under-appreciated. A theory of the evolution of norm psychology must explain its open-ended plasticity (179-182). They point out that there is ample evidence from both ethnography and history that humans can come to accept and endorse very different normative systems. This is a prima facie puzzle for anyone who links the evolution of norm psychology to a specific social effect: for example motivating whole-hearted commitment to one's own in situations of inter-group conflict (Bowles 2008). It is true that Boyd and Richerson, in widely cited modelling work, show that once norms of any kind are established they can be stabilised by punishment (Boyd/Richerson 1992). But that does not explain the origin of a capacity to understand, internalise and enforce arbitrary norms. Showing that just about any norm is stable once 
it is established and backed by serious-enough punishment does not show how norms establish in the first place. Stability explanations are not in themselves origin explanations.

Importantly, from Buchanan and Powell's point of view, this plasticity extends to 'inclusive' moral systems: ones which extend moral consideration beyond the circle of potentially mutually beneficial co-operation. It is true that this historical and ethnographic evidence primarily concerns reflective morality: an agent's explicit moral (or normative) commitments. But there is a lot more to norm psychology than explicit moral commitments. A lot of our normative life is run by 'system one' cognitive mechanisms (Kahneman 2011): fast, unreflective, automatized. But reactive and reflective normativity interact (Sterelny 2010). In recent WEIRD countries a good deal of reactive normative disgust of homosexuality has faded (presumably as a slow response to changes in explicit commitments and consequent changes in social and developmental environments) while smoking and obesity have become targets of reactive moralising disgust. So Buchanan and Powell are on safe ground in claiming that normative cognition in general is plastic: plasticity is not confined to explicit moral commitments. I suspect they are on fairly safe ground in arguing that this extends to possibility, and partial actuality, of inclusive normative psychologies, including our reactive norm psychology. This is important to Buchanan and Powell, for they aim to debunk strong versions of 'tribal instincts' accounts of the evolution and psychology of normative cognition (Richerson and Boyd 2001). On some versions of tribal-instinct accounts, evolved human nature limits true moral concern to members of our own community, and so, the argument goes, various liberal normative projects about, for example, global justice are utopian.

I agree that Buchanan and Powell should reject these 'evoconservative' arguments. As they show, these conservative arguments underrate the plasticity of norm psychology; understate the importance of institutional structures; and understate the relative independence of those structure from individual normative profiles of the individuals in the societies housing those institutions. But while I agree that the evoconservative view is deeply flawed, I found Buchanan and Powell's positive explanation of normative plasticity unpersuasive (on 188-192). Buchanan and Powell develop their account through the example of the water flea and the metaphor of a toggle (or dial). The water flea is equipped with a facultative adaptation for defence against predation. If in the course of development, the emerging flea picks up cues that predators are heavy in the environment (from chemical traces in the water), the flea develops an armoured body. But that is expensive. So absent the cue, the flea develops without armour. The cue throws a switch or a toggle, choosing between distinct developmental pathways. Analogously, Buchanan and Powell suggest that norm psychology is adaptively plas- 
tic. In circumstances in which there are environmental cues of resource scarcity, pathogen threat or external aggression, children develop with a tribal norm psychology, one which primes loyalty to an in-group, and readily leads to hostility to out-groups. In developmental environments in which there are cues of cooperative relations with out-groups, and with few or no cues of serious resource stress or pathogen threat, children develop more inclusive norm psychologies. Consequently, they are more apt to regard out-group members as having some moral standing, not treating them purely instrumentally. ${ }^{7}$

For this picture to be right, the environment in which norm psychology evolved must quite often have favoured an outward and open attitude to neighbouring communities, and Buchanan and Powell cite evidence of trade and long distance movement of material as evidence supporting this view of our past (191). I agree, of course, that hostility was not the default state between adjacent communities in the Pleistocene (though I am sure it was one of the possibilities). Even so, I think there are three problems with this line of thought. First, it sits rather oddly with the analysis of inclusive moralities as luxury goods (210-212): an option only for the relatively wealthy and secure. While I do not think Pleistocene life was perpetually on the brink of inter-community conflict or starvation, levels of violence within communities were probably high (judging from forager ethnography (Boehm 2012). Moreover, while life expectancies were probably reasonable after the survival of childhood vulnerability (Hill/Kaplan 1999), death from childhood disease was probably quite frequent. Second, it overlooks the fact that forager residential groups were nested within larger unit-ethnolinguistic groups, sometimes covering quite large ranges-and so some of the evidence of trade and raw material movement probably indicates movement within ethnolinguistic units; the tribes of the tribal instinct (Layton/O'Hara et al. 2012). But most seriously, it is hard to see how evidence of trade (and other material movement) selects for anything more than a strategic attitude towards outsiders: cooperate if and to the extent that pays. By the lights of Buchanan and Powell, that would not be a shift to an inclusive norm psychology.

Can I do better? In a couple of previous papers, I have argued that the emergence of explicit norms (or perhaps a great expansion of the role of explicit norms in social life) was due to a transition in the social and economic foundations of human life in something like the last 100k years of the Pleistocene (Sterelny 2014; Sterelny forthcoming). In part the emergence of explicit norms was a response to

7 Since the distinction between inclusive and exclusive norm psychologies is one of degree, Buchanan and Powell suggest that a dial rather than a switch is a better metaphor for the ways developmental flexibility is tuned to environmental cues. 
to the invention of high velocity projectile weapons, but perhaps also it was a response to cultural innovations, like the elaborate systems of kinship now characteristic of all ethnographically known forager cultures, and the systems of reciprocation common to many of them. These were profound changes. The economic organisation of cooperation increasingly depended on forms of reciprocation and exchange rather than immediate return mutualism, and the temporal and spatial scale of social life expanded. While the band (the overnight camp or residential group) remained the focus of day-to-day interaction, the band became nested in a larger social whole. As a consequence, band members became part of a broader community in which some members would only see one another occasionally. Moreover, to the extent that logistic mobility became important (Binford 1980), foraging parties chasing specific resources might spend days or more away from their residential group. Ties were no longer reinforced by daily or almost daily interaction amongst all the members of a community.

In these papers, I argued that while cooperation in these more complex social and economic worlds was still (potentially) very profitable-even essential-it was more cognitively and motivationally challenging. It could not depend solely on affiliative emotions sustained by daily interaction. Moreover, in these more complex environments what counted as cooperation or defection was no longer at all obvious. In addition, motivating response to defection was more difficult, for interests were no longer automatically aligned against a defector. If we are all engaged in a joint project-as with immediate return mutualism-and Powell either fails to do his share, or tries to seize the proceeds, we are all threatened with loss. But if Powell fails to reciprocate aid from Buchanan, the rest of us might not be at all affected. So I suggested that explicit norms emerged to both reduce the ambiguity of these transactions $-{ }^{8}$ to make it as clear as possible who has defected and who has not-and to motivate responses to defections. ${ }^{9}$

As I see it, the plasticity of norm psychology is linked to the emergence of explicit norms. On the analysis defended here, a significant fraction of the norms that guide social life have to be explicit (i) to play the key role reducing ambiguity about whether an agent has defected or not. This reduction in ambiguity is important initially for the focal agent in his/her decision making, and then, if there has been defection, it matters in generating consensus in the local environment about an appropriate response. (ii) Norms often need to be taught. For example, some norms of resource division are very elaborate, where both role and specific

8 Boyd 2016 makes the same suggestion.

9 This picture presupposes the prior evolution of more implicit norms that are nonetheless intrinsically motivating. Here I piggy-back on some ideas of Jonathan Birch (Birch in preparation). 
kin relationships matter. It would be very difficult to just pick-up those norms from just watching the practises they guide. ${ }^{10}$ Moreover, in many small world environments, norms are embedded in, and warranted by, narratives that are part of the ritual life of the community. They are ancestral instructions and advice. (iii) The norms of a group are not fixed once and for all (despite occasional romantic notions about the timeless stability for forager life, as in (Gammage 2011)). They could hardly be, as the social and environmental conditions communities face change over time, sometimes very sharply. No doubt change in both environment and norm is often tacit, slow, barely noticed by the community. But not always, perhaps especially if there is a crisis. Norms must be explicit to be debated, contested, decided upon. New Zealand's history records the poignant example of the Moriori, a pacifist Polynesian community living on the Chatham Islands. In 1838 they had news that a predatory community of Maori were on their way from New Zealand to invade, and they debated whether to retain their pacifist norms in the face of this existential threat (King 1989). For this to be possible, those norms must be overt and acknowledged rather than implicit in customary practice.

Norms have to be explicit to be targets of public reason and public discussion. But once they are explicit, the plasticity of norm psychology is much less puzzling. For explicit, reflective norm psychology is not encapsulated: it is at least to some extent integrated with the cognitive mechanisms which support the more general phenomena of belief formation and public reasoning. Moreover, to the extent that our explicit reflective normative commitments interact with our more reflex-like, reactive, type one norm-guided responses, the plasticity of the explicit aspects of norm psychology drives plasticity of the implicit aspects. So on my view, the plasticity of our norm psychology is a by-product of the evolutionary forces that drove a transition to partially explicit normative systems. There probably are limits to that plasticity. But Buchanan and Powell are surely right in claiming that we have no evidence that the norms of liberal democracy have crunched into those limits. But while I agree with that conclusion, I see a different path to it, one mediated by selection for making (some) implicit

10 A famous and much cited example is (Alvard/Nolin 2002). Another is given early in Gould 1969, where the proper division of a kangaroo depends on kinship relations to the successful hunter. 


\section{Conclusion}

Let me finish with a brief summary. I think there are reasons to prefer an alternative account of the evolution of norm psychology, one giving greater weight to changes in the organisation, connectivity and subsistence economy within communities, rather than one more focussed on relations between communities. However, even if I am right about that, Buchanan and Powell's most important empirical claim stands. Human norm psychology is adaptable and in particular it is responsive to the more general processes of belief formation and public discourse. There may be limits to that adaptability and, in particular, there is imperfect integration of explicit normative commitments with automatized reactions. But there is no reason to deny that humans can develop significantly inclusive norm psychologies. I do however have a serious reservation about their substantive conception of moral progress. It begs the question not just against outright moral nihilism but against partial, relationship-based accounts of moral commitment. There are traces of relationship-based normative intuitions even in WEIRD worlds. In many traditional societies, it is taken for granted that primary commitments are to kith and kin. To resist these exclusive, relationship-based views of the grounds of obligation, Buchanan and Powell need something they do not provide: an evolutionarily plausible, entirely naturalistic account of the truth-makers of moral claims that delivers impartial, inclusive moral norms. Good luck with that.

\section{References}

Alvard, M./D. Nolin (2002), Rousseau's Whale Hunt? Coordination Among Big Game Hunters, in: Current Anthropology 43(4), 533-559

Binford, L. (1980), Willow Smoke and Dogs' Tails: Hunter-Gatherer Settlement Systems and Archaeological Site Formation, in: American Antiquity 45, 4-20

Birch, J. (in preparation), Normative Guidance and Skilled Action

Boehm, C. (2012), Moral Origins: The Evolution of Virtue, Altruism, and Shame, New York

Bowles, S. (2008), Conflict: Altruism's Midwife, in: Nature 456 (20 November 2008), 326-327

Boyd, R. (2016), A Different Kind of Animal: How Culture Made Humans Exceptionally Adaptable and Cooperative, Princeton

-/P. Richerson (1992), Punishment Allows the Evolution of Cooperation (or Anything Else) in Sizable Groups, in: Ethology and Sociobiology 13, 171-195

Gammage, W. (2011), The Biggest Estate on Earth: How Aborigines made Australia, Sydney

Gibbard, A. (1990), Wise Choices, Apt Feeling, Cambridge/MA

Gould, R. A. (1969), Yiwara: Foragers of the Australian Desert, Sydney-London

Hill, K./H. Kaplan (1999), Life History Traits in Humans: Theory and Empirical Studies, in: Annual Review of Anthropology 28, 397-430 
Kahneman, D. (2011), Thinking, Fast and Slow, London

Kim, N./M. Kissel (2018), Emergent Warfare in Our Evolutionary Past, London

King, M. (1989), Moriori: A People Rediscovered, Auckland

Layton, R./S. O'Hara/A. Bilsborough (2012), Antiquity and Social Function of Multilevel Social Organiization Among Human Hunter-Gatherers, in: International Journal of Primatology 33, 215-245

Richerson, P./R. Boyd (2001), The Evolution of Subjective Commitment to Groups: A Tribal Instincts Hypothesis, in: Nesse, R. (ed.), Evolution and The Capacity for Commitment, ?????, $186-220$

Sterelny, K. (2010), Moral Nativism: A Sceptical Response, in: Mind and Language 25, 279-297

- (2014), A Paleolithic Reciprocation Crisis: Symbols, Signals, and Norms, in: Biological Theory 9, 65-77

- (2016), Cooperation, Culture, and Conflict, in: The British Journal for the Philosophy of Science 67, 31-58

- (forthcoming), Norms and Their Evolution, in: Henley, T./E. Kardas/M. Rossano (eds.), Handbook of Cognitive Archaeology: A Psychological Framework, London

-/B. Fraser (2017), Evolution and Moral Realism, in: British Journal for the Philosophy of Science 68, 981-1006 